\title{
Composite Sustainable Indicators Framework for Cost Assessment of Land Transport Mode in Lebanon Cities
}

\author{
Firas Barraj*, Youssef Attalah \\ Department of Civil and Environmental Engineering, Beirut Arab University, Beirut, Lebanon \\ Email: ^firasbarraj23@gmail.com, Youssef.attalah@bau.edu.lb
}

How to cite this paper: Barraj, F. and Attalah, Y. (2018) Composite Sustainable Indicators Framework for Cost Assessment of Land Transport Mode in Lebanon Cities. Journal of Transportation Technologies, $\mathbf{8}$, 232-253.

https://doi.org/10.4236/jtts.2018.83013

Received: May 22, 2018

Accepted: July 28, 2018

Published: July 31, 2018

Copyright $\odot 2018$ by authors and Scientific Research Publishing Inc. This work is licensed under the Creative Commons Attribution International License (CC BY 4.0).

http://creativecommons.org/licenses/by/4.0/

\section{cc) (i) Open Access}

\begin{abstract}
The aim of the work performed in this paper is to present a composite indicators framework to guide sustainable transportation planning in Lebanon by assessing the sustainability marginal cost of Land Transport modes used mostly based on ICE (internal combustion engine) auto dependence. The framework covers 6 indicators of the triple bottom line of sustainability (economy, society, and environment): operating cost, energy consumption, noise exposure, congestion delay, emissions, and safety. The framework process follows an evaluation toolkit that monitors the cost implied from listed individual indicators of transport mode. Moreover, this evaluation methodology can be used to estimate to an acceptable degree the cost variation resulting from transport mode modifications within same geographical zone. This cost variance is the main interest of investors and decision makers seeking profits and successful results of their transportation planning process. A case study is executed in Lebanon GBA (Greater Beirut Area), where the annual cost of an alternative consisting of light rail transit (LRT) to passenger cars (PC) system is assessed; applying the stated methodology. Results show clearly an environmental amelioration with a reduction of 4,651,817,100 MJ of energy and 181,936 ton of $\mathrm{CO}_{2}$ emissions in addition to a saving of $255,643,035 \$$ annually.
\end{abstract}

\section{Keywords}

Sustainable Transportation, Socio-Economical \& Environmental Effect of Sustainable Mobility, Transport Safety, Transport Cost Framework

\section{Introduction}

There are large amount of literature discussing the subjects of sustainability/ 
sustainable transportation, performance evaluation and the methods of applying sustainability for transportation agencies.

\subsection{Sustainability and Sustainable Development}

Sustainability, explored in terms of the theories of sustainable development, can be described by many expressions, in the majority of them the three dimensions (social, economical and environmental) appear clearly. A clear relation links the dimensions together i.e. Economic systems are contained within a social framework; similarly, society exists within the natural environment. These should be taken into account when following termed as a triple bottom line approach to sustainability emerged. Indeed, a lot of sustainability definitions deal with these three dimensions e.g. "sustainability is not about threat analysis, it is about system analysis specifically, how environment, economic and social systems interest to their mutual advantages and disadvantages at various space based scales of operations" (Transportation Research Board 1997).

Sustainability role shine in the compromise between conflicting set of goals (reducing use of resources, increasing economy growth, achieving social equity) and several demands desirable from different elements of society, each according to his interest.

That defined sustainability role as the solution that meets challenges through integrated solutions rather than through fragmented approaches that meet one of those goals at the expense of the others. And it takes a long-term perspective-one that's focused on the present and future-Institute for Sustainable Communities (ISC 1997) [1].

The terms of sustainability and sustainable development emerge in various events, conferences and can be traced by several publications [2] [3].

However, the majority of work covering sustainability unavoidably point out at 1987 report for the United Nations World Commission on Environment and Development (the Brundtland Commission report) [4]. As examined by Jones et al. [5], the Brundtland definition of sustainability is so popular due to the fact that it presents a broad agenda that even entities with conflicting interests or goals can agree upon. On the other hand, the Brundtland work has been criticized for focusing too much on human development and needs. Other approaches involve the Natural Step Approach framework, suggested by Robert [6], and the concept of Natural Capitalism [7], which sees the natural environment as the primary interest of sustainability.

\subsection{Sustainability and Sustainable Transportation}

Transportation systems have been described as the "lifeblood" of cities in recognition this critical role (V. R, 1999) [8]. Transport is linked to all aspects of our life. Our natural environment, economic, prosperity, and social wellbeing all depend on transportation systems that are safe, clean, efficient, and equitable. Conversely, the social, economic, and environmental impacts of transport are 
framed as critical issues that can challenge the sustainability of cities and regions.

A sustainable development cannot be achieved without a sustainable transport system. The sustainability within transportation is described by a series of characteristics according to the center of sustainability (CST 2005) [9]:

1) Allows the basic access needs of individuals and societies to be met safely and in a manner consistent with human and ecosystem health, and with equity within and between generations.

2) Is affordable, safe, operates efficiently, offers choice of transport mode, and supports a vibrant economy.

3) Limits emissions and waste, minimizes consumption of non-renewable resources, limits consumption of renewable resources to the sustainable yield level, reuses and recycles its components, and minimizes the use of land and the production of noise.

Another description of sustainable transportation was addressed by Banister who portrayed sustainable mobility paradigm involving four primary elements (Technology, demand management, integrated land use and transportation planning, and public awareness and acceptance) [10].

A review of the literature marks certain common boundaries among various sustainable transportation initiatives and definitions; these widely involve concerns about environmental impacts, assurance on safety, affordability, and accessibility of transportation services, etc.

\subsection{Frameworks, Indicators, and Performance Measures for Sustainability in Transportation}

Performance measures (or indicators) are measurable criteria aiming to monitor progress toward achieving targets. A considerable amount of knowledge exist at the international scientific community concerning individual factors (indicators) affecting sustainability (Munier, 2005) [11]. In addition, Rand ET al 2004, Litman 2009 have set a list of several indicators covering the three sustainability aspects (Economical-Social-Environmental) [12]. That led the majority of researches to follow a convenient way to measure the level of sustainability by using indicators (ECTS 2001, Hakkinen 2007) [13] [14].

When introducing an integral methodology of sustainability performance measurement to be utilized by a transportation agency, it is helpful to observe how performance indicators are mixed into frameworks and applied.

The commonly-usable performance measurement process scan be characterized as having this procedure [15]: 1) define objectives; 2 ) determine targets; 3) measure performance; 4) evaluate performance versus targets; and 5) assess and review process.

From a transportation viewpoint, the authors debate the requirements of robust sustainability frameworks involving flexibility, understanding of trade-offs, maintaining linkages with agency goals and objectives, addressing needs of all 
stakeholders.

Internationally, to convince any of transport agencies into modifying their system to another more sustainable, major studies and researches have been executed to find scientific tools and methods to measure sustainability performance. Researchers seeks suitable ways to transfer this knowledge to transport managers, decisions makers and municipalities to start correcting their mistaken vision of profit which should not only based on increasing operating economic growth but should be seen from the sustainability triple bottom line perspective.

While literature provides several examples of sustainability indicators and guidance of their selection, a very scarce documented examples move through the framework application process involving defining sustainability and applying indicators measurement.

In this paper, we present a composite indicator framework to monitor the sustainability cost performance of Transport modes in Lebanon and similar countries cities. The framework follows the performance measurement process, applies indicators measurement and covers 6 indicators of the triple bottom line of sustainability (economy, society, and environment): operating cost, energy consumption, noise exposure, congestion delay, emissions, and safety. The cost measurement is executed through an evaluation toolkit emanating from these indicators.

\section{Lebanon Case}

Lebanon similar to the majority of third world countries lack immensely regarding the field of transportation sustainability in comparison to the modern world as all of his land transport system is mostly based on private gasoline ICE cars (85\% of land transport) and on petroleum resources. Even, its public transport system, characterized by poor management, consists of old diesel buses and vans in poor condition that doesn't provide reliability or security for passengers' trips. Road traffic accidents - the leading cause of death by injury and the 10th leading cause of all deaths globally-make up a surprisingly significant portion of the worldwide burden of ill-health. Car accidents reached 4205 in Lebanon in 2012. In addition, $25 \%$ of $\mathrm{CO}_{2}$ emissions come from the land transport sector which comes only second to electricity as the most national excessive energy consumers. That led Lebanon to be in the lead of countries that are still in the birth stage regarding the sustainability knowledge and the ways of applying its principles, especially in transport sector which is drowning in complete mess causing negative consequences on all vital partitions.

In order to challenge the consequences resulting from the huge unorganized investment in Lebanon transport sector reliable on non renewable resources and on traditional expanding roads solution, new plans and programs need to be followed by government and organizations to adjust the negative direction of the index of the sustainability of transport system. The rectification process initiates by identification of the problem which is obviously the auto dependence ICE 
mobility in these countries. The second step will be to offer solutions, propose logical plans and strategies to the faced problem. Utterly, the principal work is to formulate valid methods to monitor the development of transport sustainability in the city regarding the suggested solutions.

At Lebanon level, little has been done by both researchers and government in the transportation sustainability field, to provide methods and techniques to measure the cost performance of unsustainable mobility systems within its cities. The studies previously done care most for environmental cases regarding transport sector as Greenhouse gases emitted (National Greenhouse Gas Inventory Report For Transport Sector 2015) [16] and influence on climate change (Lebanon TNA report for Climate Change 2012) [17]. Some researches investigate the Lebanese passenger transport energy consumption (Electris et al., 2009) [18], while others focus on driving conditions and market share to estimate operating costs of the Lebanese system (Mansour, C. and Zgheib, E., 2012) [19]. But, the topic considering the annual economic loss resulting from Lebanon strictly unsustainable mobility system is rarely considered a major case for government and effectives parties.

\section{Sustainability Cost Assessment Framework}

The need to measure sustainability appeared at the same time as the concept of sustainability. Figure 1 illustrates the flowchart of the proposed sustainable cost assessment framework using a cost evaluation toolkit that covers indicators of the triple bottom line of sustainability.

The framework presented is valid for Lebanon and similar nations facing the same identified problem which is the total ICE auto dependence mobility and working towards achieving the sustainability in transportation sector.

The framework include principal relevant aspects important to the transport system sustainability, there are 6 aspects grouped according to category:

1) Economic dimension (operating cost, congestion cost)

2) Environmental dimension (noise exposure, energy consumption, émissions)

3) Social dimension (safety and crashes cost)

\subsection{Cost Evaluation Toolkit}

Figure 2 illustrates the selected sustainability indicators used in toolkit formulation and their respective components.

For all transport modes, a distance based model may be applied to calculate total operating cost, noise exposure, energy consumption and $\mathrm{CO}_{2}$ emissions costs in a desired duration of time.

A distance based model is formed by multiplying (total distance travelled by mode during a time $t) \times$ specific factor depending on vehicle and fuel type.

This toolkit will focus on the distance based model to calculate the outcome of the 4 mentioned indicators and manual formulated approaches for others. 


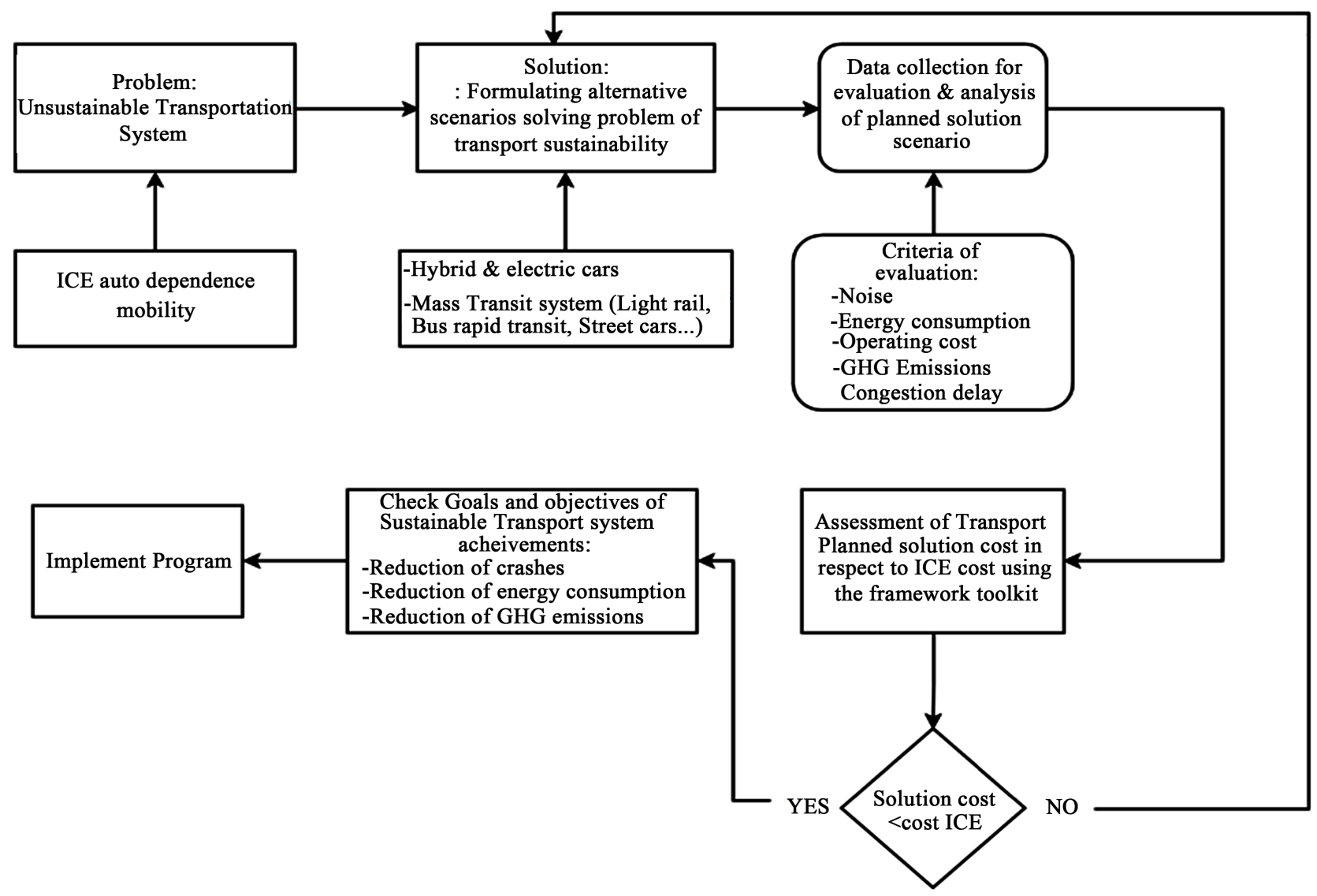

Figure 1. Framework for sustainable transportation planning process in Lebanon.

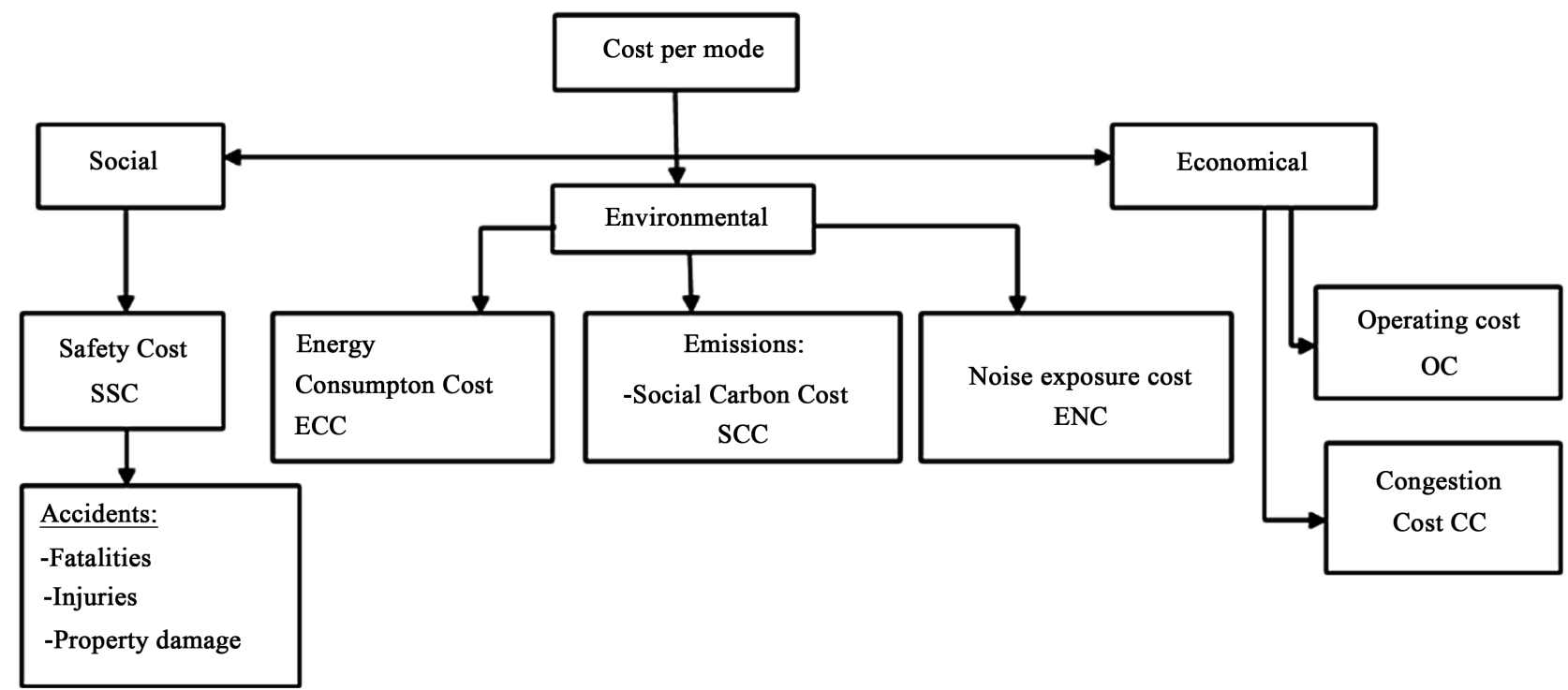

Figure 2. Cost evaluation toolkit sustainable indicators components.

\subsubsection{Distance Base Model}

The degree of difficulty in calculating transportation emissions depends largely on which gases are included in the analysis. In most cases, $\mathrm{CO}_{2}$ emissions are relatively straightforward to estimate, since they are primarily dependent on only 
two factors: the type and quantity of fuel burned. $\mathrm{N}_{2} \mathrm{O}$ and $\mathrm{CH}_{4}$ emissions, on the other hand, depend largely on the emissions control equipment used (e.g., type of catalytic converter). Since $\mathrm{N}_{2} \mathrm{O}$ and $\mathrm{CH}_{4}$ emissions comprise a relatively small proportion of overall transportation emissions, only $\mathrm{CO}_{2}$ emissions estimates are included in this tool.

(Emission/distance unit), (energy consumption/distance unit) and (operating cost/distance unit) factors are used to calculate the outcome by multiplying it by aggregated distance data. The emission factor represents the fraction of carbon component in fuel delivered into atmosphere after the chemical oxidation take place.

Distance data units can be in several forms: vehicle kilometers travelled, freight ton-kilometers, passenger-kilometers traveled. Distance data and (emission, operating cost, noise cost and energy consumption) factors varies according to vehicular engine category. So the following equation outlines the approach to calculating the cost based on distance data traveled:

$$
\begin{gathered}
\mathrm{CO}_{2} \text { Emissions/mode }=\sum_{i=1}^{n} \mathrm{Di} \times \mathrm{Ei} \\
S C C=\left(\sum_{i=1}^{n} D i \times E i\right) \times \operatorname{cost} 1 \text { ton } \mathrm{CO}_{2} \\
\text { Energy consumption/mode }=\sum_{i=1}^{n} D i \times E c i \\
E C C=\left(\sum_{i=1}^{n} D i \times E c i\right) \times \operatorname{cost} 1 \mathrm{MJ} \\
O C=\sum_{i=1}^{n} D i \times O c i \\
E N C=\sum D v \times N \times N c
\end{gathered}
$$

where,

Di: Distance data travelled according to vehicular engine of type $i$

$E i$ : (Emission/distance unit) factor for vehicular engine of type $i$

Oci: (Operating cost/distance unit) factor for vehicular engine of type $i$

$E c i$ (Energy/distance unit) factor for vehicular engine of type $i$ in $\mathrm{MJ}$

$\Sigma D_{V}=$ total distance traveled by vehicle mode in VKM.

$N c=$ marginal noise costs per distance depending on mode type.

$N=$ number of vehicle of transport mode.

The $\mathrm{SC}-\mathrm{CO}_{2}$ is a measure, in dollars, of the long-term damage done by a ton of carbon dioxide $\left(\mathrm{CO}_{2}\right)$ emissions in a given year. The value of $41 \mathrm{USD} / \mathrm{t} \mathrm{CO}_{2}$ is adopted (Van Den Bergh and Botzen, 2014) [20].

$1 \mathrm{MJ}=0.0076$ gal \& $1 \mathrm{US}$ gallon price $=3 \$ \rightarrow 1 \mathrm{MJ}$ cost $=0.0228 \$$.

\subsubsection{Time Framed Model for Safety Indicator Cost}

The outcome will be based on collecting transport accidents data for a near previous time $\mathrm{n}$ (years), and assigning it into three components: fatalities, injuries and property damages.

The following equations outlines the model to calculating the average of each of these components based on time framed approach 
- Mean of fatalities per mode $M F=R a \times N \times F a$

- Mean of injuries per mode $M I=R a \times N \times I a$

where,

$$
\begin{aligned}
& R a=\text { average rate of accident } 1 \text { vehicular unit of mode }=\sum_{i=1}^{n}\left(\frac{A i}{N i}\right) / n \\
& F a=\text { average rate of fatality/1 accident of mode }=\frac{\sum_{i=1}^{n} F i}{n} / \frac{\sum_{i=1}^{n} A i}{n} . \\
& I a=\text { average injuries rate/1 accident of mode }=\frac{\sum_{i=1}^{n} I i}{n} / \frac{\sum_{i=1}^{n} A i}{n} . \\
& F=\text { number of mode fatalities per year } \\
& I=\text { number of mode injuries per year. } \\
& A=\text { number of mode accidents per year } \\
& N=\text { number of mode vehicular units for year i } \\
& I=\text { year number } 1,2, \cdots, n, \\
& \qquad S S C=M F \times \operatorname{cost} 1 \text { fatality }+M I \times \text { cost } 1 \text { injury } \\
& \qquad+R a \times N \times \text { cost property damage/accident }
\end{aligned}
$$

\subsubsection{Congestion Cost Approach}

Congestion cost approach interested basically in roadway transport wheeled mode because rail mode transport by principle uses separated exclusive lanes for travel and usually should not face congestion issues.

Calculating congestion cost is calculating the cost of 2 main consequences delivered from it:

- Congested roadway vehicle running cost

- Loss due to value of time for in vehicle travel (stopping + slow movement)

In order to measure the roadway vehicle running cost, a road congestion status need to be assigned to one of the categories according to various parameters as shown in Table 1 [21].

Secondly, based on the roadway congestion category, an estimated value can be deducted for the loss per vehicle mile from Table 2 according to specified parameters as nature of road and vehicle type [21].

The following equation is used to find the first cost component:

Table 1. Roadway congestion categories.

\begin{tabular}{rccccc}
\hline & Extreme & Severe & Heavy & Moderate & $\begin{array}{c}\text { Free } \\
\text { flow }\end{array}$ \\
\hline Highway & & & & & \\
Avg. daily traffic per lane & $>25,000$ & $20,001-25,000$ & $17,501-20,000$ & $15,001-17,500$ & $<15,000$ \\
Avg. vehicle speed (mph) & 32 & 35 & 38 & 45 & 60 \\
Arterial & & & & & \\
Avg. daily traffic per lane & $>10,000$ & $8501-10,000$ & $7001-8500$ & $5001-7000$ & $<5500$ \\
Avg. vehicle speed (mph) & 21 & 23 & 27 & 30 & 35 \\
\hline
\end{tabular}

Source: Transportation Cost and Benefit Analysis II-Congestion Costs Victoria Transport Policy Institute. 
Table 2. Estimated highway congestion costs (cents per vehicle mile).

\begin{tabular}{ccccccccccc}
\hline & \multicolumn{3}{c}{ Rural highways } & \multicolumn{3}{c}{ Urban Highways } & \multicolumn{3}{c}{ All Highways } \\
\cline { 2 - 10 } & High & Med. & Low & High & Med & Low & High & Med & Low \\
\hline Automobile & 3.76 & 1.28 & 0.34 & 18.27 & 6.21 & 1.64 & 13.17 & 4.48 & 1.19 \\
Pickup \& Van & 3.8 & 1.29 & 0.34 & 17.78 & 6.04 & 1.6 & 11.75 & 4 & 1.06 \\
Buses & 6.96 & 2.37 & 0.63 & 37.59 & 12.78 & 3.38 & 24.79 & 8.43 & 2.23 \\
Single Unit Trucks & 7.43 & 2.53 & 0.67 & 42.65 & 14.5 & 3.84 & 26.81 & 9.11 & 2.41 \\
Combination Trucks & 10.87 & 3.7 & 0.98 & 49.34 & 16.78 & 4.44 & 25.81 & 8.87 & 2.32 \\
All vehicles & 4.4 & 1.5 & 0.4 & 19.72 & 6.71 & 1.78 & 13.81 & 4.7 & 1.24 \\
\hline
\end{tabular}

Source: Transportation Cost and Benefit Analysis II-Congestion Costs Victoria Transport Policy Institute.

$$
\text { Running cost } R c=\sum_{i=1}^{n} D i \times L c i
$$

where,

Di: distance data traveled by vehicle type $i$

Lci: congestion loss/distance factor by vehicle type $i$

- Value of time proposed methodology is divided into 2 divisions based on trip purpose model (work or non work trip travel time delays) and both rely on the average hourly income salary of households.

Average hourly income salary $H=\frac{\text { average monthly salary per household }}{\text { nb of working hours per week } \times 4.33}$

For the work purpose trip, the following equation can be used:

$$
L 1=\Delta T(H+0.33 H)=(T f-T i) \times 1.33 H
$$

where

Delay $\Delta T=(T f-T i)=$ actual trip time-free flow trip time in hours

L1: Loss due to delays in travel time per capita trip.

$H$ : Average hourly income salary

The Toolkit for the Economic Evaluation of transport projects(World bank 2005) suggest a coefficient of $0.33 \mathrm{H}$ to mirror additional costs related with work trip of an employee and income rate such as overheads, paid holidays, sickness, etc [22].

\section{For the non work purpose trip}

There is no proper basis matching between the value of the non-working hour and salary rate theoretically, however its value is associated to income, though any salary change should be expressed in a variation in the value of non-working hour. Due to lack in local data, its amount is taken as 30 percent of the hourly salary rate as recommended by the World Bank Toolkit [22].

$$
L 2=\Delta T \times 0.3 H
$$

where,

Delay $\Delta T=(T f-T i)=$ actual trip time-free flow trip time in hours.

L2: Loss due to delays in travel time per capita trip.

$H$ : Average hourly income salary. 
The total value of time loss can be estimated using the equation:

$$
T=\sum_{i=1}^{n} Z i \times L 1+\sum_{i=1}^{n} Y i \times L 2
$$

where,

$\sum Z i$ represent the passengers facing delay during work trip

$\sum Y i$ represent the passengers facing delay during a non work trip.

$$
\text { Congestion cost } C C=R c+T \text { in } \$
$$

To summarize all costs:

Total cost per mode $=C C+O C+E C C+E N C+S S C+S C C$

\section{Case Study: The Cost Assessment of ICE Passenger Cars Mode in GBA and Their LRT (Light Rail Transit) Alternative Using the Framework and the Proposed Evaluation Toolkit}

The Greater Beirut Area (GBA) location addressed in Figure 3 extends from Nahr-el-Damour south to Nahr-el-Kalb north, enclosing more than $40 \%$ of the population estimated to be 5,102,830 in 2011, including foreign workers and Palestinian refugees (Central Administration Statistics CAS 2013).

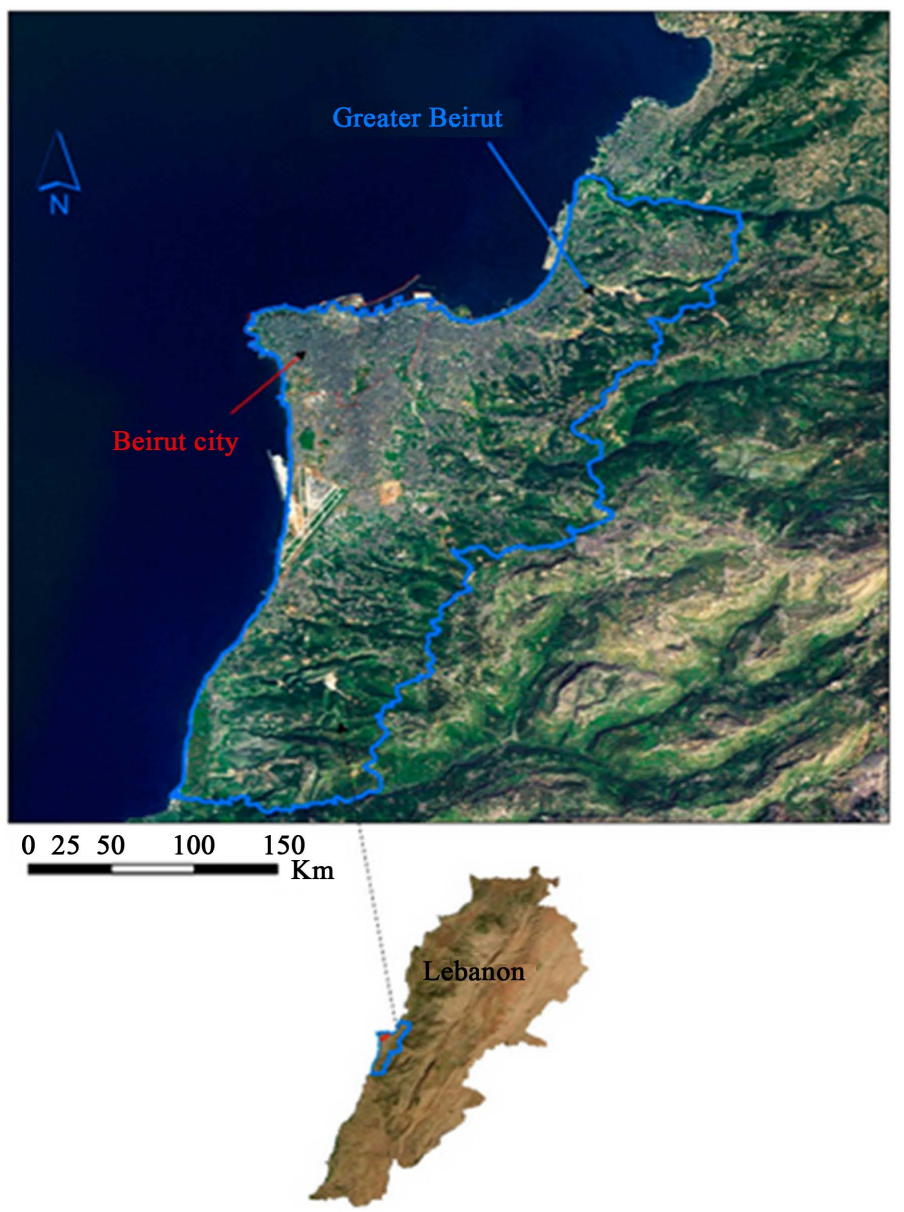

Figure 3. Location of the greater Beirut area. 
Transport systems in GBA can be described as strictly unsustainable. Traffic conditions are mostly congested as shown in Figure 4 especially at the entrances to Beirut, with daily passenger trips amounting to around 2.8 million daily automobile passenger trips in 2007, which are expected to increase to 5 million in 2015 (Ministry of Public Works and Transport, 2007). The average speeds during the day along the major axes in the GBA range between 15 and $30 \mathrm{~km} / \mathrm{hr}$, dropping to $10 \mathrm{~km} / \mathrm{hr}$ and less in the commercial districts within the city at peak times (MOE, 2012 i.e. ministry of environment) [17].

\subsection{Future LRT Plan \& Assessment}

Installing a light railway system for Lebanon aims to account for multiple objectives:

- Access needs of individuals

- Environmental protection

- Economic vitality

Shifting to rail transport will be stepping into an environmentally-friendly mass transport option. The particularity of rail is its high transport capacity per trip compared to other modes of transportation (Golinska et al., 2012). In this case, the energy requirements per passenger-trip dramatically decrease and savings are not only in terms of energy and emissions, but in space as well since one train transporting two hundred passengers would take less space than two hundred cars, for example.

As a first step, a light rail line must be implemented from Jounieh to Beirut airport. Such line is considered as a congestion relief for the whole area of Beirut, especially on Dawra highways and jell el dib which are a nightmare for Lebanese citizens since the activity of vehicles along this line is considered very high active and an implementation of such system will find its success easily.

From Jounieh to Beirut is a highly active area, daily congestion is always expected along this line and the peak hour spread all day. The light rail line passes

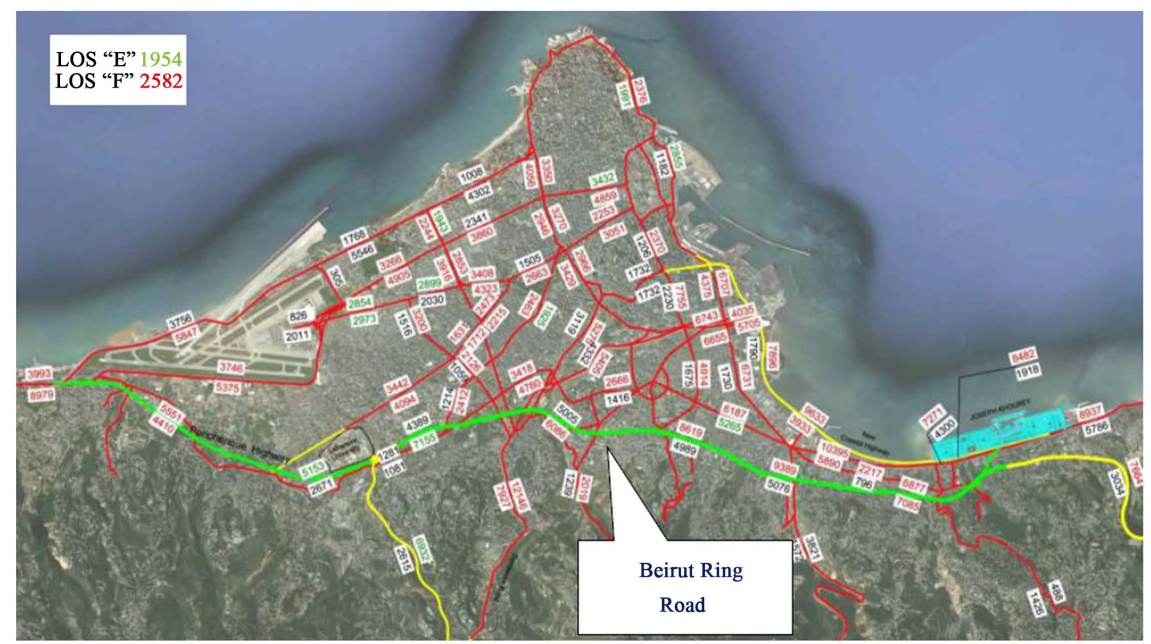

Figure 4. GBA congestion status (Council for development and reconstruction lebanon 2015). 
inside Beirut through its central district which adds a sense of civilization and modernization to the city and help moving inside the city easier. The last destination would be Beirut airport and this is essential because of the précising dates of travelers and the importance of this facility (Figure 5).

\section{Reasons for choosing this location}

1) Highest population density in Lebanon is concentrated along the chosen direction of light rail line. This will form a good launching for the project.

2) Most businesses and resorts are distributed along the path and this will improve mobility and economy as well.

3) Most congested roads and highways are along this area

4) High percentages of accidents that takes place on daily basis due to poor maintenance of roads and absence of safety precautions.

\section{Light Rail Transit Demand and Analysis \\ Trip end model}

Greater Beirut Area is located in the central coastal area of Lebanon. It covers an area of $233.2 \mathrm{~km}^{2}$, which corresponds to $2.2 \%$ of the Lebanese territory. The average population density in GBA is approximately 6200 inhabitants $\mathrm{km}^{2}$ [23] and the average number of cars per household was 1.8 [24]. To estimate the expected percentage of transit mode split, urban travel factor UTF is calculated using trip end model curve as indicated in Figure 6:

$$
\mathrm{UTF}=\frac{1}{1000}\left(\frac{\text { household }}{\text { auto }} \times \frac{\text { persons }}{\mathrm{mi}^{2}}\right)=27
$$

$\Rightarrow$ The expected percentage of (Lrt) transit mode split is approximately $=$ $43 \%$.

\subsection{Data Collection}

- The 2012 Lebanese fleet database shows a total of 1.58 million registered vehicles, of which $85 \%$ consisting of ICE passenger car $=1,343,000$ PC (Lebanon Lebanon Technology Needs Assessment report 2012) [17].

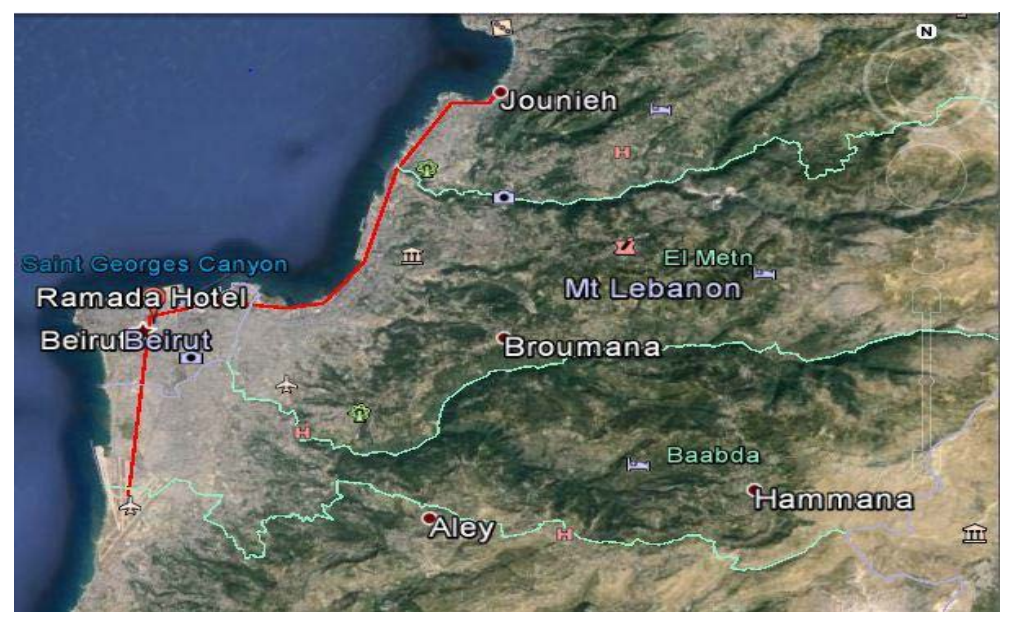

Figure 5. Proposed light rail line layout $(27 \mathrm{~km})$. 


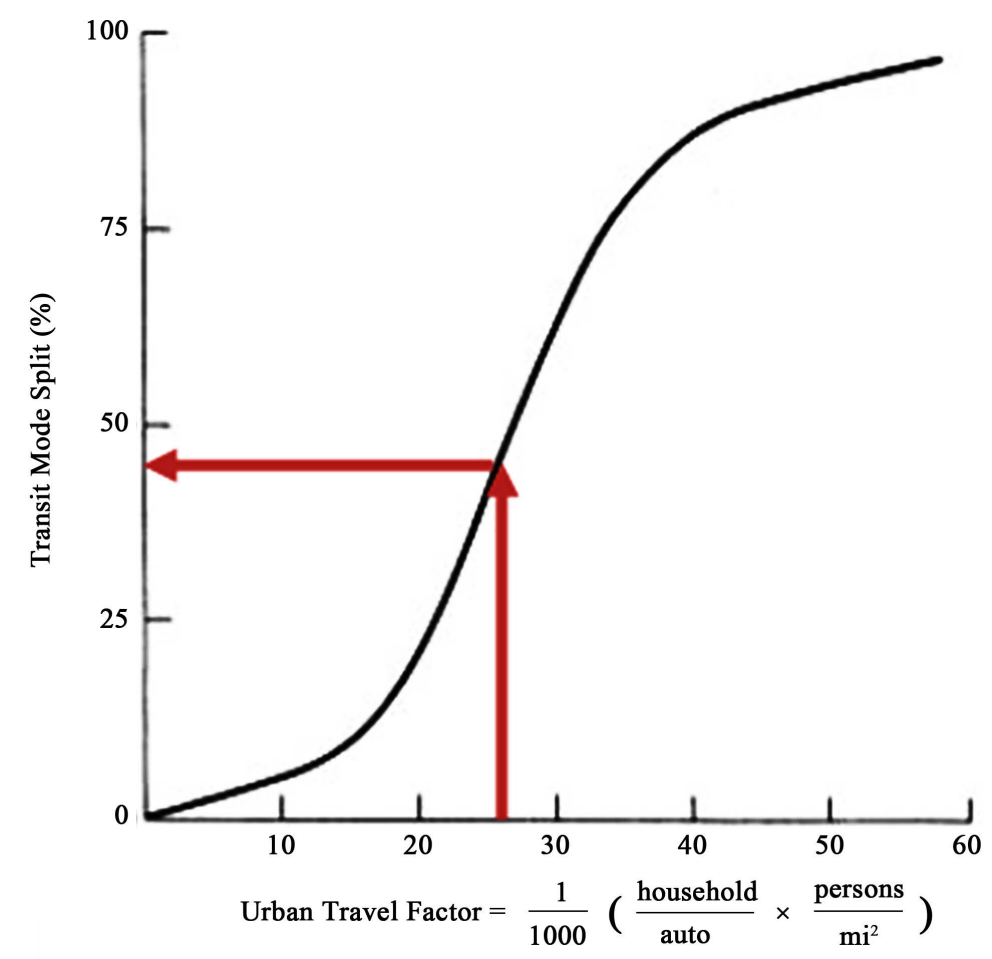

Figure 6. Transit mode split versus urban travel factor.

- The final number of passenger cars in circulation was $1,108,328$ vehicles (MOIM, 2012 i.e. Lebanese Ministry of Interior and Municipalities).

Due to lack of recent studies by Lebanon ministries, to estimate the 2016 fleet size, the 2012 passenger fleet is increased because the sector of car sale has experienced a positive trend in growth over the period 2012-2016 by growing at an average annual rate of 3.3\% (Bank med analysis of Lebanon transport sector) [25] as shown in Table 3.

The 2016 fleet size estimated is close to the 1,232,229 PC used in the article "Influence of boundary conditions and anthropogenic emission inventories on simulated $\mathrm{O}_{3}$ and PM 2.5 concentrations over Lebanon (2016)" [26].

- $40 \%$ of Lebanese passenger cars circulate within Greater Beirut Area (MOIM, 2016 i.e. Lebanese Ministry of Interior and Municipalities) $=>$ the number of passenger cars circulating in GBA for 2016 is taken 505,051.

- $75 \%$ of GBA trips are work based trip and $25 \%$ are non work based trip, and the average mobility rate $=3$ trip/passenger/day (Team international 2013) [26].

Passenger cars PC are distributed according to engine size as shown in Table 4.

- The available data on the average annual traveled distance per vehicle class is considered 15,000 km (MOE/UNDP/GEF, 2015) [17].

\section{Operating cost of driving PC}

The operating cost will be divided on its 3 principal costs depending on distance: 
Table 3. New car sales (2010-2016).

\begin{tabular}{ccc}
\hline year & New car sales & Number of PC \\
\hline 2010 & 36,112 & $1,037,694$ \\
2011 & 34,522 & $1,073,806$ \\
2012 & 35,477 & $1,108,328$ \\
2013 & 36,109 & $1,144,437$ \\
2014 & 37,816 & $1,182,253$ \\
2015 & 39,361 & $1,221,614$ \\
2016 & 41,014 & $1,262,628$ \\
\hline
\end{tabular}

Table 4. $\mathrm{CO}_{2}$ emissions and fuel consumption regarding distribution of passenger car fleet according to engine size (MOE 2015).

\begin{tabular}{cccc}
\hline Engine size & Percentage & $\mathrm{CO}_{2}$ emissions $(\mathrm{g} / \mathrm{km})$ & Fuel consumption $(\mathrm{L} / 100 \mathrm{~km})$ \\
\hline Small $(<1.4 \mathrm{~L})$ & $8 \%$ & 185 & 7.95 \\
Medium $(1.4-2.0 \mathrm{~L})$ & $32 \%$ & 200 & 8.48 \\
Large $(>2.0 \mathrm{~L})$ & $60 \%$ & 218 & 9.24 \\
\hline
\end{tabular}

- Fuel consumption $(\mathrm{L} / 100 \mathrm{~km}) \& 1 \mathrm{~L}=0.9 \$$.

- Engine oil change recommended each $3000 \mathrm{~km}$ of $32-46 \$$ according to size (car dealership surveys in Lebanon).

- Average (maintenance-tire-tax-insurance-salvage value) mixed cost of 21 cents/veh.km (Mansour, C. and Zgheib, E., (2012).

For different engine size, the overall operating cost is ranging between 29 and 31.7 cents per veh.km which is close to the value of 33 cents estimated by AAA organization study (Your Driving Costs'study, ORLANDO, 2016).

- Occupancy rate of a vehicle is taken as 1.2 passengers per car (MOE/UNDP/ GEF, 2015).

○ The road transport sector in Lebanon considered having high passenger transport energy intensity in 2007, estimated at 2.45 - $3.08 \mathrm{MJ} /$ passenger-kilometer (Electris et al., 2009).

\section{Crashes data}

- The accidents data used are taken from kunhadi organization and Beirut traffic center database; records shown in Table 5 \& Table 6 are extracted from Lebanese ISF (internal security forces) reports and are used to calculate the values of $\mathrm{Ra}, \mathrm{Fa}$ and Ia.

Based on Accident data for the 2010 year (last study executed), we get approximately:

Cost of accident fatality $=360,145 \$$.

Cost of accident injury $=46,990 \$$.

Cost of property damage/accident $=27,567 \$$ accident. 
Table 5. The stats of accidents, injuries, and fatalities.

\begin{tabular}{cccc}
\hline Year & Crashes & Injuries & Fatalities \\
\hline 2010 & 4583 & 6517 & 549 \\
2011 & 4447 & 6040 & 508 \\
2012 & 4804 & 6697 & 595 \\
2013 & 4675 & 6137 & 649 \\
2014 & 4907 & 6463 & 657 \\
2015 & 4287 & 5458 & 576 \\
2016 & 3277 & 4450 & 443 \\
\hline
\end{tabular}

Table 6. Accidental costs (USD Million).

\begin{tabular}{cccc}
\hline cost & fatality & injury & property damage \\
\hline total cost & 197.72 & 324.52 & 126.34 \\
\hline
\end{tabular}

Source: Traffic control center for Lebanon.

- $\mathrm{Ra}=$ average rate of accident $/ 1 \mathrm{PC}=0.00389$

- $\mathrm{Fa}=$ average rate of fatality $/ 1$ accident of $\mathrm{PC}=0.128373$

- $\mathrm{Ia}=$ average injuries rate $/ 1$ accident of $\mathrm{PC}=1.348031$

\subsection{Calculation and Discussion}

\begin{tabular}{ccccc}
\hline Number of vehicles/day & Occupancy & $\begin{array}{c}\text { Number of } \\
\text { Passengers/day }\end{array}$ & $\begin{array}{c}\text { Mobility } \\
\text { trip rate }\end{array}$ & $\begin{array}{c}\text { Passengers } \\
\text { trips/day }\end{array}$ \\
\hline 505,051 & 1.2 & 808,081 & 3 & $1,818,183$ \\
\hline
\end{tabular}

Passengers trips $/$ day $=$ Number of vehicles/day $\times$ occupancy $\times$ mobility rate $(18)$

\begin{tabular}{cccc}
\hline \multirow{2}{*}{ GBA } & \multicolumn{3}{c}{ Mode share demand } \\
\cline { 2 - 4 } & LRT & PC & Total \\
\hline Percentage & $43 \%$ & $57 \%$ & $100 \%$ \\
Passengers trips/day & 781,819 & $1,036,364$ & $1,818,183$ \\
Passengers/day & 260,606 & 345,455 & 606,061 \\
PC number equivalent & 217,172 & 287,879 & 505,051 \\
\hline
\end{tabular}

To monitor the annual cost performance of LRT, a comparison should be done between LRT trips and same trips number by PC using the framework assessment toolkit.

\section{For LRT:}

From an operational perspective, a service with operating period 18 hours, 100 seconds headway and LRT vehicles with a capacity of 400 persons would be adequate for accommodating ridership. 
Daily Demand = 260,606 passengers.

- Productivity $=$ operate period/headway $\mathrm{x}$ length $=17,496 \mathrm{veh} . \mathrm{km} /$ day .

- Annual LRT productivity $=6,386,040$ veh.km.

Transporting 260,606 passengers making an annually average of 15,000 km travel is equal:

Pkm $=$ Passengers number $\times$ average annual travelled distance

$=260,606 \times 15,000=3,909,090,000 \mathrm{~km}=2,443,181,250$ miles.

\section{Cost Evaluation}

1) Environmental Noise Cost

\begin{tabular}{cccccc}
\hline \multicolumn{5}{c}{ Environmental Noise Cost ENC/year } \\
\hline $\begin{array}{c}\text { Number of } \\
\text { vehicle units }\end{array}$ & $\begin{array}{c}\text { Distance travelled } \\
(\mathrm{km}) / \mathbf{1} \text { unit }\end{array}$ & $\begin{array}{c}\text { Mode } \\
\text { distance }(\mathrm{km})\end{array}$ & $\begin{array}{c}\text { marginal } \\
\text { noise costs, } \\
€ \text { per 1000 vkm }\end{array}$ & ENC $(€)$ \\
\hline PC & 217,172 & 15,000 & $3,257,580,000$ & 8.8 & $28,666,704$ \\
LRT & 39 & 163,745 & $6,386,040$ & 273.4 & $1,745,944$ \\
\hline
\end{tabular}

ENC for PC mode $=34,400,045 \$ \&$ ENC for LRT mode $=2,095,132 \$$

Marginal noise cost is estimated at $8.8 €$ for a passenger car and $273.4 €$ for passenger train per $1000 \mathrm{vkm}$ (Values from CE Delft et al. 2011) [28].

2) For safety indicator cost

\begin{tabular}{cc}
\hline & For fleet size of $\mathrm{PC}=\mathrm{N}=217,172$ \\
\hline MF & 109 \\
MI & 1139 \\
SSC & $116,056,084 \$$ \\
\hline
\end{tabular}

LRT excels in safety and has a record clearly superior to that of automobile travel. Among transit modes, LRT is the safest. Data submitted to FTA document that LRT's safety record is 0.7 accidents per billion miles of vehicle travel (BTS, National Transportation Statistics, 2003) [29].

The accident rate of LRT is approximately touching 0 considering annual mileage of millions instead of billions miles $\rightarrow \mathrm{A}=0 \rightarrow \mathrm{Ra}=0 \rightarrow \mathrm{MF}=\mathrm{MI}=0 \rightarrow$ $\mathrm{SCC}=0 \$$.

\section{3) Congestion delay indicator cost}

Average hourly income salary $H=\frac{\text { average monthly salary per household }}{\text { nb of working hours per week } \times 4.33}$

In Lebanon, the Labor Law indicates a maximum of 48 working hours/week. As well, the working hours/week in private sector (48 hours) are not the same for the public sector (near 40 hours).

In this study, an average of 44 working hours is adopted considering the average of 40 and 48 weekly working hours. Delays at the majority of intersections in GBA are ranging from 5 to 30 minutes per trip (MOE/URC/GEF, 2012). 
For the purpose of this research, it is assumed that the delay per passenger trip is $17 \mathrm{~min}$ based on the average minimum $5 \mathrm{~min}$ of delay per passenger trip and the maximum 30 min of delay per passenger trip.

Average Monthly Salary (After Tax $)=1032$ \$ [30].

$$
H=\frac{1032}{44 \times 4.33}=5.41 \$
$$

- Value of working hour $=1.33 H=7.19 \$$

- Value of non working hour $=0.3 H=1.62 \$$

\section{For LRT mode:}

The separate exclusive lanes and priority right of way for LRT mode allow it to avoid this problem $\rightarrow$ CC for LRT $=0 \$$.

\section{For PC mode}

\begin{tabular}{|c|c|c|c|c|c|c|c|}
\hline \multicolumn{2}{|c|}{ Number of vehicles/day } & Occupancy & \multicolumn{2}{|c|}{$\begin{array}{c}\text { Number of } \\
\text { Passengers/day }\end{array}$} & \multicolumn{2}{|c|}{$\begin{array}{l}\text { Mobility } \\
\text { trip rate }\end{array}$} & $\begin{array}{l}\text { assengers } \\
\text { trips/day }\end{array}$ \\
\hline \multicolumn{2}{|l|}{217,172} & 1.2 & \multicolumn{2}{|c|}{260,606} & \multicolumn{2}{|l|}{3} & 781,820 \\
\hline Trip purpose & Percentage & $\Sigma \mathrm{Z}$ & $\Sigma \mathrm{Y}$ & L1 & L2 & $\Sigma \mathrm{Z} \times \mathrm{L} 1$ & $\Sigma \mathrm{Y} \times \mathrm{L} 2$ \\
\hline Work trip & 75 & 572,865 & & 1.53 & & 876,483 & \\
\hline \multirow[t]{3}{*}{ Non work trip } & 25 & & 190,955 & & 0.46 & & 87,840 \\
\hline & & & \multicolumn{3}{|c|}{ Travel time Loss per day } & \multicolumn{2}{|c|}{$964,322 \$$} \\
\hline & & & \multicolumn{3}{|c|}{ Travel time Loss per year } & \multicolumn{2}{|c|}{$351,977,640 \$$} \\
\hline
\end{tabular}

The average speeds during the day along the major axes in the GBA range between 15 and $30 \mathrm{~km} / \mathrm{hr}$ so Beirut falls under the extreme roadway congestion condition.

A high congestion cost for all highways to be taken as $0.1317 \$ /$ vehicle mile $=$ $0.0823 \$ /$ vehicle $\mathrm{km}$ (Litman et al. 2011) [21].

\begin{tabular}{cccc}
\hline Number of vehicles & Annual travelled distance $(\mathrm{km})$ & Lci $(\$ /$ veh.km) & vehicle running loss Rc (\$) \\
\hline 217,172 & $3,257,580,000$ & 0.0823 & $268,098,834$
\end{tabular}

$$
=>C C=R c+T=620,076,474 \$
$$

\section{4) Operating cost indicator for PC mode}

Take into consideration the same distribution of engine size for the volume of 217,172 PC:

\begin{tabular}{ccccc}
\hline Mode & Engine size & $\begin{array}{c}\text { Number of } \\
\text { vehicle units }\end{array}$ & $\begin{array}{c}\text { Annual distance } \\
(\mathrm{km}) / 1 \text { unit }\end{array}$ & $\begin{array}{c}\text { Total Annual } \\
\text { distance }(\mathrm{km})\end{array}$ \\
\hline & $<1.4 \mathrm{~L}$ & 17,374 & 15,000 & $260,610,000$ \\
PC & $\mathbf{1 . 4}-\mathbf{2 . 0 \mathrm { L }}$ & 69,495 & 15,000 & $1,042,425,000$ \\
& $>\mathbf{2 . 0 \mathrm { L }}$ & 130,303 & 15,000 & $1,954,545,000$ \\
\hline
\end{tabular}




\begin{tabular}{cccccc}
\hline \multirow{2}{*}{ Mode } & \multirow{2}{*}{ Engine size } & Fuel consumption $(\mathrm{L})$ & \multicolumn{3}{c}{ Operating cost OC/year in \$ } \\
\cline { 4 - 6 } & & & Fuel cost & Oil change cost & Mixed cost \\
\hline & $<1.4 \mathrm{~L}$ & $20,718,495$ & $18,646,646$ & $2,084,880$ & $54,728,100$ \\
PC & $1.4-2.1 \mathrm{~L}$ & $88,397,640$ & $79,557,876$ & $10,163,644$ & $218,909,250$ \\
& $>2.1 \mathrm{~L}$ & $180,599,958$ & $162,539,962$ & $22,477,268$ & $410,454,450$ \\
& & Total & $260,744,484$ & $34,725,792$ & $684,091,800$ \\
& & & & $979,562,076$ & \\
\hline
\end{tabular}

\section{5) Social Carbon cost SCC for PC mode}

\begin{tabular}{ccccc}
\hline Mode & Engine size & $\mathrm{CO}_{2}$ emissions $(\mathrm{kg} / \mathrm{km})$ & $\begin{array}{c}\text { Annual } \mathrm{CO}_{2} \\
\text { emissions }(\mathrm{kg})\end{array}$ & $\begin{array}{c}\text { Social carbon } \\
\text { cost SCC/year in \$ }\end{array}$ \\
\hline PC & $\mathbf{1 . 4}-\mathbf{2 . 0 \mathrm { L }}$ & 0.185 & $48,212,850$ & $1,976,727$ \\
& $>\mathbf{2 . 0 \mathrm { L }}$ & 0.2 & $208,485,000$ & $8,547,885$ \\
& & 0.218 & $426,090,810$ & $17,469,723$ \\
\end{tabular}

6) Energy consumption cost ECC for PC mode

\begin{tabular}{|c|c|c|c|c|c|c|}
\hline Mode & $\begin{array}{l}\text { Engine } \\
\text { size }\end{array}$ & occupancy & $\begin{array}{c}\text { Annual } \\
\text { passengers } \\
\text { distance }(\mathrm{Pkm})\end{array}$ & $\begin{array}{c}\text { Energy } \\
\text { consumption } \\
(\mathrm{MJ} / \text { pas.km) }\end{array}$ & $\begin{array}{c}\text { Annual } \\
\text { energy } \\
\text { consumption } \\
(\mathrm{MJ})\end{array}$ & $\begin{array}{c}\text { Annual } \\
\text { Energy } \\
\text { consumption } \\
\text { cost ECC (\$) }\end{array}$ \\
\hline \multirow{4}{*}{ PC } & $<1.4 \mathrm{~L}$ & 1.2 & $260,610,000$ & 2.45 & $638,494,500$ & $14,557,675$ \\
\hline & $1.4-2.1 \mathrm{~L}$ & 1.2 & $1,042,425,000$ & 2.75 & $2,866,668,750$ & $65,360,047$ \\
\hline & $>2.1 \mathrm{~L}$ & 1.2 & $1,954,545,000$ & 3.08 & $6,019,998,600$ & $137,255,968$ \\
\hline & & & & & Total & $217,173,690 \$$ \\
\hline
\end{tabular}

As for LRT mode, distance data units are passengers miles and their respective factors are adopted as follow:

Average Operating Cost (\$/pass. mile) $=0.69[31]$

GHG emission $\left(\mathrm{lbCO}_{2} /\right.$ pass. mile $)=0.41[32]$

Energy consumption (MJ/pass. mile) $=0.56[33]$

\begin{tabular}{ccccccc}
\hline Mode & $\begin{array}{c}\text { Annual } \\
\text { Pass. Miles }\end{array}$ & $\begin{array}{c}\text { Annual } \\
\text { Operating } \\
\text { Cost OC }(\$)\end{array}$ & $\begin{array}{c}\text { Annual } \\
\text { GHG } \\
\text { emissions } \\
(\text { ton CO })\end{array}$ & $\begin{array}{c}\text { Annual } \\
\text { Emissions } \\
\text { Cost SCC }(\$)\end{array}$ & $\begin{array}{c}\text { Energy } \\
\text { consumption } \\
(\mathrm{MJ})\end{array}$ & $\begin{array}{c}\text { Annual Energy } \\
\text { consumption } \\
\text { cost ECC (\$) }\end{array}$ \\
\hline LRT & $2,443,181,250$ & $1,685,795,063$ & 500,852 & $20,534,938$ & $1,368,181,500$ & $31,194,538$ \\
\hline
\end{tabular}

A summary of the above calcuation is given by the table (Table 7) and the figure below (Figure 7) showingthe performance cost measures of the 2 analysed modes, concluding with a net saving coming out of adopting the LRT model instead of current ICE mode of transport. 
Annual Cost Assesment of Transport Mode Choice

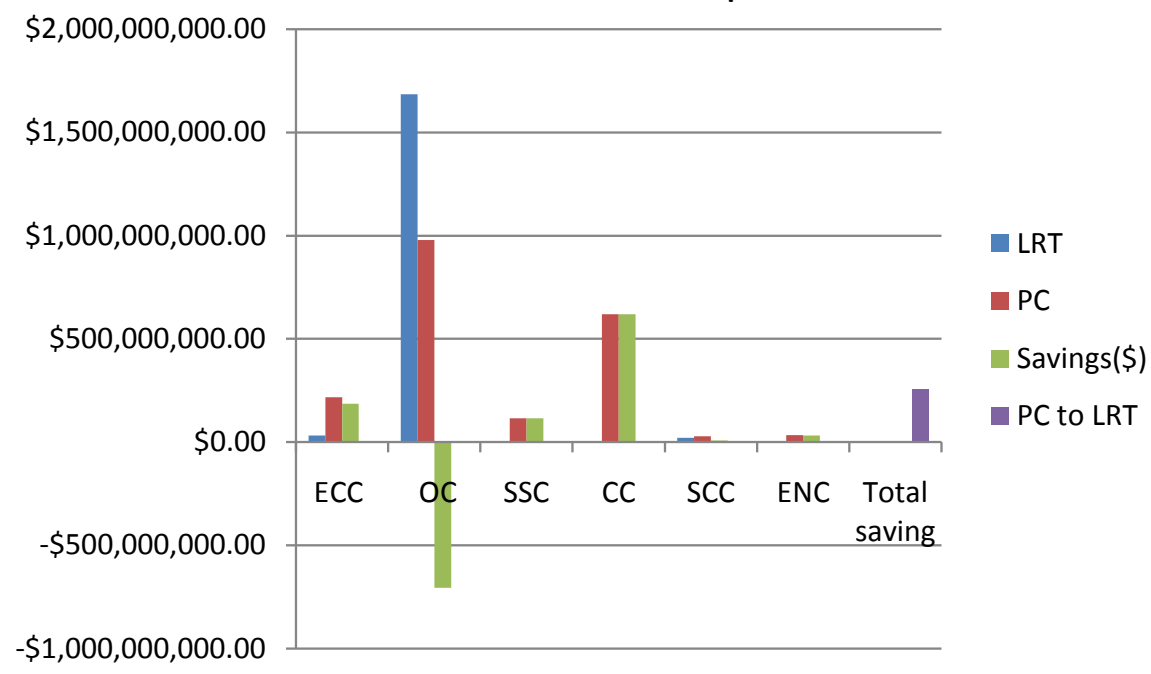

Figure 7. LRT, ICE and ICE to LRT modification cost analysis results.

Table 7. Case study summary.

\begin{tabular}{ccccccc}
\hline Mode & ECC & OC & SSC & CC & SCC & ENC \\
\hline LRT & $31,194,538$ & $1,685,795,063$ & 0 & 0 & $20,534,938$ & $2,095,132$ \\
PC & $217,173,690 \$$ & $979,562,076 \$$ & $116,056,084 \$$ & $620,076,474$ & $27,994,335 \$$ & $34,400,045$ \\
\multirow{2}{*}{ Savings (\$) } & $185,979,152$ & $-706,232,987$ & $116,056,084$ & $620,076,474$ & $7,459,397$ & $32,304,913$ \\
& & & & & & \\
& & & & \\
& & &
\end{tabular}

\section{Conclusion and Future Work}

Starting from sustainable indicators (social, economical and environmental) to formulate a cost toolkit to measure the performance of ICE transport system and evaluate their modification is the main interest that this paper tries to deliver. That will help ICE auto dependent countries suffering from sustainability lateness to begin considering this vital issue and propose solutions that can be assessed in front and achieve the maximum benefit.

The case study assessed and the LRT solution in GBA show clearly an environmental amelioration with a reduction of 4,651,817,100 MJ of energy and 181,936 ton of $\mathrm{CO}_{2}$ emissions in addition to a saving of $255,643,035 \$$ annually.

This notable improvement come only through a modification involving less than $20 \%$ of the total volume of gasoline car running in Lebanon and considering only GBA as the main congestion zone. Altering transport mode from private gasoline car to mass transit in Lebanon who is paying approximately a bill of millions dollars annually due to his unsustainable mode of transport proved to be efficient and beneficial to the country in all sustainable dimensions.

From framework methodology viewpoint, there remain some interesting topics to explore as further environmental indicators involving other GHG emissions (NO and NOX emissions) can be included. As well, more social indicators as equity and accessibility can be added, other economic values as employment 
and affordability could also take part in the performance measurement process. In fact, more researches covering a bigger set of indicators will make the framework more accurate and give a more comprehensive form.

\section{Acknowledgements}

The authors wish to thank Beirut Arab University Dean and civil engineering department for their support; they provided insight and expertise that greatly assisted the research, although they may not agree with all of the interpretations/conclusions of this paper. We also thank Traffic center of Beirut, the ministry of environment and the ministry of interior and municipalities who provided us with the data required to complete our work.

\section{Conflicts of Interest}

The authors declare no conflicts of interest regarding the publication of this paper.

\section{References}

[1] The President's Council on Sustainable Development (1997) ISC's Elements of a Sustainable Community Task Force Report, Washington. https://www.iscvt.org/impact/definition-sustainable-community/

[2] Hall, R.P. (2006) Understanding and Applying the Concept of Sustainable Development to Transportation Planning and Decision-Making in the U.S. PhD Dissertation, MIT, Cambridge.

[3] Kelly, C. (2007) Origins of Sustainability Report for Task, Appraisal of Sustainability Project Report. Institute for Transport Studies, University of Leeds, Leeds, UK.

[4] U.N. World Commission on Environment and Development (1987) Our Common Future: Report of the World Commission on Environment and Development (A/42/427).

[5] Jones, C., Baker, M., Carter, J., Jay, S., Short, M. and Wood, C. (2005) Strategic Environmental Assessment and Land Use Planning: An International Evaluation. Sterling, VA: Earthscan, London.

[6] Robèrt, K.-H. (2009) The Natural Step. International Institute for Environment and Development (IIED), London.

[7] Hawken, P, Lovins, A. and Lovins, L.H. (1999) Natural Capitalism: Creating the Next Industrial Revolution. Little, Brown and Co., Boston.

[8] Vuchic, V.R. (1999) Transportation for Livable Cities. Rutgers Center for Urban Policy Research, United States.

[9] Gudmundsson, H., Hall, R.P., Marsden, G. and Zietsman, J. (2015) Sustainable Transportation: Indicators, Frameworks, and Performance Management. Springer, Berlin Heidelberg.

[10] Banister, D. (2008) the Sustainable Mobility Paradigm. Transport Policy, 15, 73-80. https://doi.org/10.1016/j.tranpol.2007.10.005

[11] Munier, N. (2005) Introduction to Sustainability Road to a Better Future. Springer, Dordrecht.

[12] Litman, T. (2013) Well Measured-Developing Indicators for Sustainable and Livable Transport Planning. Victoria Transport Policy Institute, Victoria, Canada. 
[13] ECTS (2001) Transport Safety Performance Indicators. European Transport Safety Council, Brussels.

[14] Hakkinen (2007) Trends and Indicators for Monitoring the EU Thematic Strategy on Sustainable Development of Urban Environment. VTT Technical Research Centre, Finland.

[15] Marsden, G. and Thanos, S. (2008) Measuring Wider Economic Benefits of Transport: A Case Study in Good Practice for Indicator Selection, Deliverable C2, DISTILLATE Project.

[16] MOE/UNDP/GEF (2015) National Greenhouse Gas Inventory Report and Mitigation Analysis for the Transport Sector in Lebanon. Beirut, Lebanon.

[17] MOE/URC/GEF (2012) Lebanon Technology Needs Assessment Report for Climate Change. Beirut, Lebanon.

[18] Electris, C., Raskin, P., Rosen, R. and Stutz, J. (2009) The Century Ahead: Four Global Scenarios Technical Documentation. Tellus Institute, Boston.

[19] Mansour, C. and Zgheib, E. (2012) Existing Driving Conditions in Greater Beirut Area.

[20] Van den Bergh, J.C.J.M. and Botzen, W.J.W. (2014) A Lower Bound to the Social Cost of $\mathrm{CO}_{2}$ Emissions. Nature Climate Change, 4, 253-258. https://doi.org/10.1038/nclimate2135

[21] Litman, T. (2011) Transportation Cost and Benefit Analysis II-Congestion Costs. Victoria Transport Policy Institute.

[22] Mackie, P., Nellthorp, J. and Laird, J. (2005) Notes on the Economic Evaluation of Transport Projects. Transport Notes Series No. TRN-5. World Bank, Washington DC.

[23] Faour, G. and Mhawej, M. (2014) Mapping Urban Transitions in the Greater Beirut Area Using Different Space Platforms. National Center for Remote Sensing, National Council for Scientific Research (CNRS), Beirut.

[24] Chalak, A., Al-Naghi, H., Irani, A. and Abou-Zeid, M. (2015) Commuters' Behavior towards Upgraded Bus Services in Greater Beirut: Implications for Greenhouse Gas Emissions, Social Welfare and Transport Policy. The Issam Fares Institute for Public Policy and International Affairs, American University of Beirut, Beirut.

[25] Bank Med. Market (2016) Analysis of Lebanon's Automobile Sector. Economic Research Division, Beirut.

[26] Abdallah, C., et al. (2016) Influence of Boundary Conditions and Anthropogenic Emission Inventories on Simulated O and PM Concentrations over Lebanon, Atmospheric Pollution Research.

[27] TEAM International (2013) Greater Beirut Transportation Plan, Data Collection. Report No. 4, CDR, Beirut.

[28] Korzhenevych, A. and Dehnen, N. (2014) Update of the Handbook on External Costs of Transport.

https://www.ec.europa.eu/transport/sites/transport/files/handbook_on_external_co sts_of_transport_2014_0.pdf

[29] BTS, National Transportation Statistics (2003) Tables 1-32, 2-1 and 2-4; APTA, Safety Summary by Mode, 2003. Pedestrian and Cycling Mileage Is Based on FHWA.

[30] Numbeo Organization Report (2018) Cost of Living in Lebanon. https://www.numbeo.com/costliving/country_result.jsp?country=Lebanon 
[31] Newman, P. and Worthy, J.K. (2009) Evaluating the Transport Sector's Contribution to Greenhouse Gas Emissions and Energy Consumption. Curtin University Sustainability Policy (CUSP) Institute.

[32] Hodge, T. (2009) Public Transportation's Role in Responding to Climate Change. Office of Research, Demonstration and Innovation Federal Transit Administration, DIANE Publishing.

[33] Neff, J. and White, R.A. (2016) Public Transportation Fact Book. American Public Transportation Association APTA, Washington DC. 